\title{
ESTUDO DOS VENTOS NA ÁREA CENTRAL DA CIDADE DE JUIZ DE FORA (MG): UM ENSAIO DA ESPACIALIZAÇÁO DE SEUS FLUXOS
}

\author{
THE WINDS STUDY' IN THE CENTRAL AREA TO JUIZ DE FORA \\ CITY (MG): A TEST OF THE SPECIALIZATION OF ITS FLOWS
}

ESTUDIO DE LOS VIENTOS EN LA ZONA CENTRAL DE LA CIUDAD

DE JUIZ DE FORA (MG): UNA PRUEBA DE SUS ESPACIALIZACIONES

\begin{abstract}
Daiane Evangelista de Oliveira
Mestre em Geografia - PPGEO/UFJF;

Laboratório de Climatologia e Análise Ambiental /LABCAA/UFJF

daiane.evangelista.oliveira@gmail.com
\end{abstract}

Débora Couto de Assis

cassis.debora@gmail.com

Mestre em Geografia - PPGEO/UFJF;

Laboratório de Climatologia e Análise Ambiental /LABCAA/UFJF cassis.debora@gmail.com

Franciele de Oliveira Pimentel

Mestranda em Geografia - PPGEO/UFJF;

Laboratório de Climatologia e Análise Ambiental /LABCAA/UFJF

tiele_pimentel@gmail.com

Cássia de Castro Martins Ferreira

Docente - PPGEO/UFJF;

Coordenadora do LABCAA/UFJF;

Laboratório de Climatologia e Análise Ambiental /LABCAA/UFJF cassia.castro@uff.edu.br

Yan Carlos Gomes Vianna

Mestrando em Geografia - PPGEO/UFJF;

Geógrafo responsável técnico pela estação meteorológica do INMET/UFJF;

Laboratório de Climatologia e Análise Ambiental /LABCAA/UFJF

yan.vianna@uff.edu.br 
Resumo: Ventos são complexos, mutáveis e muito imprevisíveis, podendo trazer inúmeros benefícios ou transtornos à sociedade. No entanto, ainda são poucos os estudos na climatologia brasileira que têm essa variável como elemento central da pesquisa. É partindo desse contexto e da constatação de que há em um clima urbano distintos gradientes barométricos produzidos a partir dos materiais que constituem as cidades (naturais ou antrópicos), que o presente ensaio metodológico traz como objetivo estudar os sentidos/ direçôes possíveis dos ventos em uma área no centro da cidade de Juiz de Fora (MG), considerando os possíveis fatores que viriam a influenciar no fluxo do ar (relevo e altura dos edifícios) e a formação ou não de corredores de ventos. O estudo se deu utilizando-se de coleta em campo e em laboratório, através do software ArcGIS 10, e chegou-se a conclusóes de que a direção dos ventos é variável principalmente conforme a localização do ponto e a hora do dia, apresentando constância na velocidade dos mesmos, prevalecendo as de até três quilômetros na região baixa da cidade (setecentos metros) e até seis quilômetros no ponto da UFJF (940 metros), e inconstância no sentido, não havendo direçôes predominantes.

Palavras-chave: Vento; Movimentação do ar; Fatores climáticos urbanos; Clima urbano;

Abstract: Winds are complex, changeable and very unpredictable, being able can bring numerous benefits or disorders to society. However, there are still few Brazilian climatology studies which has this variable as the central element of the research. After starting from this context, and whereas to have has different urban climate barometric gradients, produced from materials that constituent the cities (naturals or anthropics), which the objective of this study is mapping and see the possible directions of the winds at the center of Juiz de Fora (MG), considering the possible factors that would influence the air flow (relief and height of the buildings) and the formation or not of wind corridors. The study was carried out using of research in fieldand laboratory, in using make ArcGIS 10 software and arrived at the conclusions that the direction of the winds varies mainly according to the location of the point and time of day; show constancy in the speed of the winds, prevailing those of up to $3 \mathrm{~km}$ in the low region of the city (up to 700 meters) and up to $6 \mathrm{~km}$ in the UFJF point, that is located at an altitude of 940 meters of altitude; and inconstancy in the direction, with no predominant directions.

Keywords: Wind; Air movement; Urban climate factors; Urban climate;

Resumen: Los vientos son complejos, cambiantes, impredecibles, y pueden traer numerosos beneficios o los trastornos a la sociedad. Sin embargo, hay pocas investigaciones entre los estudios brasileños del tiempo que tienen esta variable como un elemento central de la investigación. Es a partir del este contexto, y el la hallazgo de que hay en un clima urbano gradientes de presión barométrica distintas producidas a partir de los materiales que constituyen las ciudades (naturales o antrópicos) que este ensayo metodológico aporta a estudiar los sentidos/posibles direcciones de los vientos en una área en el centro de la ciudad de Juiz de Fora (MG), teniendo en cuenta los posibles factores que puedan influir 
en el flujo de aire (relieve y altura de los edificios) y la formación de los corredores del vientos. El estudio se realizó utilizando la recogida en el campo y en el laboratorio, a través del software ArcGIS 10, y llegó a las conclusiones de que la dirección del viento se varía principalmente en función de la ubicación del punto y la hora del día; con una constancia de la velocidad del viento, que prevalece el hasta 3 kilómetros en la zona del centro de la ciudad (cerca del $700 \mathrm{~m}$ ) y hasta $6 \mathrm{~km}$ en el punto UFJF, que está situado a una altitud de 940 metros; yuna inconstancia en orden, sin direcciones predominantes.

Palabras clave: Viento; Movimiento Del aire; Factores climáticos urbanos; Clima urbano;

\section{INTRODUÇÃO}

A terminologia vento pode ser encontrada em poemas, músicas, livros, reportagens e em todo o folclore de uma região. E não são só os tornados e ciclones, que dada a suas magnitudes, e por causarem arritmia na ciclicidade dos tipos de tempo, que ficam registrados na memória afetiva dos indivíduos, também as brisas, que são ventos de menor intensidade estão presentes nas lembranças de uma pessoa, uma vez que podem marcar as características de uma regiáo, como no caso das brisas marinhas e de montanhas. A percepção da movimentação do ar, denominada vento, está presente direta ou indiretamente na vida dos indivíduos.

Porém, se no senso comum as observaçôes dos tipos de vento já fazem parte de todo um cotidiano em sociedade, no meio científico há ainda muitas imprecisóes e incertezas quanto às manifestaçóes do mesmo. Muito se sabe sobre a origem e principais direçóes dos ventos em grande escala, mas pouco sobre a movimentação que se dá em baixa atmosfera. A complexidade dos materiais que constituem a superfície terrestre ressalta as incertezas que possuem a movimentaçáo mecânica dos gases que constituem o ar.

Em meio urbano essa situação é ainda mais acentuada. Há nesses espaços uma coabitação de elementos naturais (relevo, corpos hídricos, vegetação) e antropizados (prédios, casas, vias de circulação, automóveis) que produzem tipologias climáticas distintas e que, dada a velocidade de mutaçáo da dinâmica social citadina, acentuam e alteram as principais direçóes de movimentaçáo do ar, desenvolvendo relaçóes climáticas muito específicas para cada sítio urbano.

Partindo dessas incertezas, e considerando a importância de se conhecer a dinâmica dos ventos, o presente ensaio metodológico traz como objetivo identificar e estudar os principais fluxos de direcionamento e velocidade dos ventos em uma área central da cidade de Juiz de Fora (MG), levando em consideração os fatores que podem influenciar no fluxo do ar e na formação de corredores de vento, tais como o relevo, a altura dos edifícios e as vias de circulação viária.

Estudos desse tipo são de fundamental importância, pois estão relacionadas à produção de energia eólica, às obras de engenharia e arquitetura, à produção agrícola e pecuária, à melhoria da qualidade do ar, além de aplicaçóes em índices de conforto térmico/sensação térmica. 


\section{REFERENCIAL TEÓRICO}

A análise da bibliografia da produçáo brasileira em climatologia indica que, se comparado com os outros elementos meteorológicos (Precipitaçáo e Temperatura do Ar), poucos estudos têm o vento como centro da investigaçáo, o que se justifica pela dificuldade encontrada na disponibilidade de aquisição de equipamentos e nas incertezas que permeiam a sua modelagem.

Buscando resgatar a presença, inconstâncias e peculiaridades em registros históricos, constata-se que há muito tempo o vento vem sendo observado e, para além da observação, tendo suas gêneses e trajetórias sendo explicadas. No senso comum do homem primitivo, por exemplo, a crença de que forças ocultas regiam a natureza e que os fenômenos naturais seriam como os sentimentos humanos (raiva, alegria, tristeza), fazia com que se justificassem as arritmias nas manifestaçóes dos ventos, e dos outros elementos meteorológicos, em analogia ao comportamento humano (ELY, 2006). Havia uma forte influência do misticismo na explicação dos acontecimentos, como no caso dos índios brasileiros que acreditavam que seres divinos regiam o clima e que enviavam ou não os ventos que trariam chuvas (SANT'ANNA NETO, 2001).

Conforme ressaltado por Ely (2006), já na Antiguidade Clássica, quando os filósofos gregos buscavam explicaçôes para certos fenômenos climáticos já se buscava o entendimento do vento, o qual era compreendido como um fluxo de ar. No entanto, é no período das grandes navegaçóes que se intensificam a criação de técnicas (ainda que rudimentares) para a mediçáo da direçáo e intensidade dos ventos, o que auxiliavam no translado marítimo de forma mais objetiva e segura, uma vez que possibilitaria a prevenção à ocorrência de tempestades e furacóes (ELY, 2006).

Alguns estudos também tiveram destaque a partir das Revoluçóes Industriais. A inserção progressiva de indústrias e de automóveis trouxe a poluiçáo do ar como um de seus transtornos, fazendo com que o entendimento do melhor local para a inserção de indústrias estivesse dentre as pautas das questóes ambientais. $\mathrm{O}$ advento do modo de produçáo capitalista exigia novas formas de pensar o espaço e o desenvolvimento de equipamentos para a obtençáo de dados dos elementos atmosféricos, dentre eles os de vento, viriam no controle e mitigação de impactos.

O advento da meteorologia sinótica é também um marco aos estudos climáticos. O entendimento dos campos barométricos significou um avanço à compreensão dos ventos, uma vez que é em decorrência do gradiente de pressão atmosférica que se tem a formação desses.

Convergindo de uma área de Alta para Baixa pressão atmosférica, tem-se que "a principal causa de movimentação do ar é o desenvolvimento de um gradiente de pressão horizontal por meio das diferenças espaciais no aquecimento superficial e das mudanças consequentes na densidade e pressão do ar" (BARRY; CHORLEY, 2013, p. 143), uma vez que "por ser gasoso, o ar obedece às leis da dinâmica dos fluidos" (MENDONÇA e DANNI-OLIVEIRA, 2007, p. 75). Essa dinâmica ocorre de forma similar nas escalas horizontais e verticais e a movimentação do ar se dá seguindo as relaçóes que existem entre atmosfera e superfície. 
Duas camadas verticais principais podem ser distinguidas na atmosfera e se portarão de maneiras distintas. Conforme ressalta Vianello e Alves (2012, p. 242):

uma é identificada como camada limite planetária, estendendo-se da superfície da Terra até, no máximo, três quilômetros de altura, compreendendo em torno de $10 \%$ da massa atmosférica... acima da camada planetária, as forças viscosas anulam-se e o escoamento não sofre os efeitos do atrito. Essa segunda região é conhecida como atmosfera livre (VIANELLO e ALVES, 2012, p. 242).

A circulação do ar nessas áreas terá características próprias e quanto mais próximas da superfície registrarão ventos com menores velocidades. Mesmo sendo o gradiente de pressão entre as áreas que irá controlar a velocidade do vento, o qual será mais veloz quanto mais forte este for (MENDONÇA e DANNI-OLIVEIRA, 2007), há elementos nesta (como prédios, casas, árvores, colinas, outros) que se portam como obstáculos à sua movimentação e exercem um efeito friccional no ar (BARRY; CHORLEY, op. cit.). Este se move "mais livremente longe da superfície, pois não está sujeito aos efeitos retardantes do atrito e da obstrução" (BARRY; CHORLEY, op. cit., p. 152).

O relevo local, por exemplo, é um fator que vem a influenciar na velocidade e direçáo dos ventos, pois as correntes de vento diminuem a velocidade quando entram em contato com as variaçóes no modelado do terreno (MASCARÓ, 1991).

Rugosidades formadas por barreiras antrópicas também retardam a velocidade dos ventos, como é o caso do papel exercido pelos materiais que constituem as cidades. Em áreas urbanas (figura 1) os ventos têm sua velocidade reduzida e a presença de construçôes civis pode favorecer ainda à formação de canyons urbanos que, dispondo-se espacialmente como uma espécie de corredor de edificaçóes elevadas, concentradas e separadas pelas vias de circulaçáo, trazem novas possibilidades de direcionamento para os ventos.

Figura 1 - Perfil de velocidade do vento em diferentes localidades
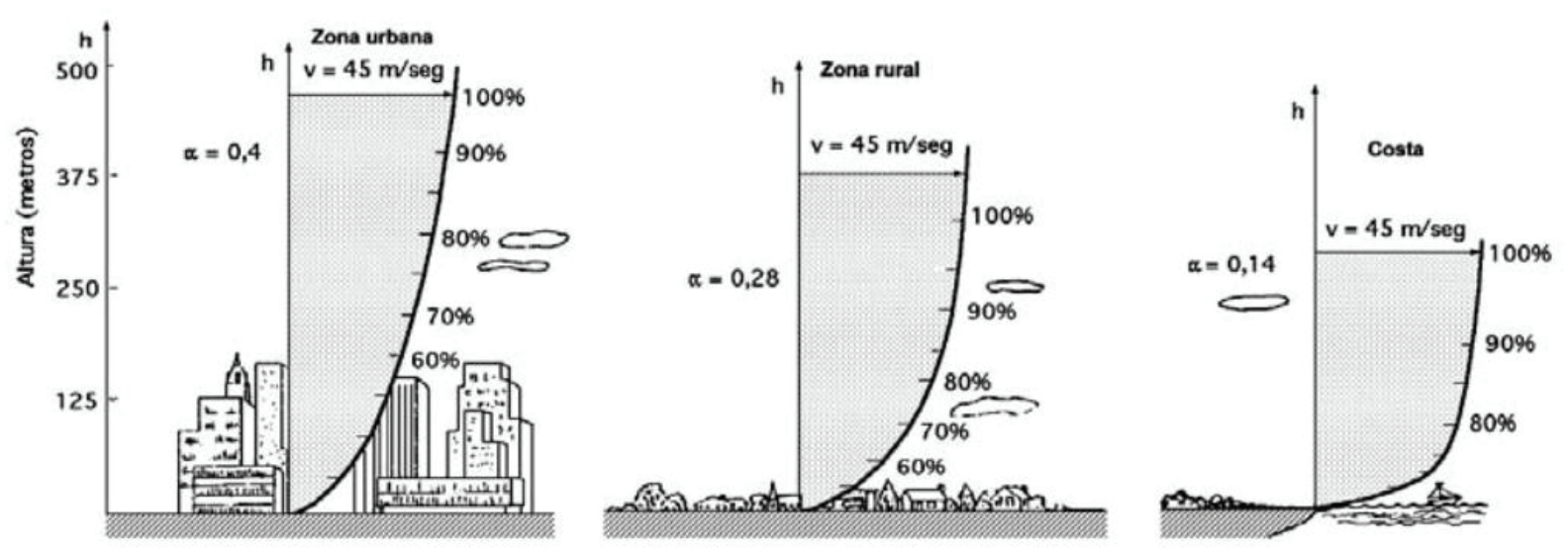

Fonte: D'iez, (2003) apud Nunes Junior (2008). 
Também a inércia térmica desses constituintes precisa ser considerada, pois podem criar campos barométricos distintos e favorecer a movimentaçáo de ventos de formação local. "Ventos locais decorrem de um gradiente de pressão local que se estabelece como resultado do aquecimento diferencial da superfície com a alternância do dia e da noite" (MENDONÇA; DANNI-OLIVEIRA, 2007, p. 79), e está exemplificada por Barry e Chorley (2013, p. 152):

Em condições normais, as velocidades do vento tendem a ser menores perto do amanhecer, quando existe pouca mistura térmica vertical, e o ar mais baixo é menos afetado pela velocidade do ar acima. Da mesma forma, as velocidades de certos ventos locais são maiores ao redor das 13-14 horas, quando o ar está mais sujeito ao aquecimento terrestre e ao movimento vertical, desse modo possibilitando um acoplamento com o movimento do ar superior (mais veloz) (BARRY; CHORLEY, 2013, p. 152).

Exemplos deste fenômeno são as brisas marítima e oceânica, a brisa terrestre e a continental e as brisas de vale e de montanha. A força que rege tais ventos apresenta muitas variáveis de formação e, se comparadas às principais forças planetárias, representam maiores problemas à sociedade (BARRY; CHORLEY, op. cit.). "As tendências diurnas se sobrepõem aos padróes de grande e pequena escala da velocidade do vento, sendo particularmente notável no caso de ventos locais" (BARRY; CHORLEY, op. cit., p. 152).

A compreensão das movimentações do ar próximo à superfície é importante (VIANELLO e ALVES, 2012). Considerar fatores como os padrões de construção urbana, a cobertura da terra e a morfologia do terreno, assim como a incidência da radiação solar (que influencia a variação diária dos ventos) e a chegada de uma massa de ar de propriedades termodinâmicas muito diferentes daquelas atuantes até então, é tornar possível aferir certas relaçóes de movimentação do ar, que não seriam possíveis em caso contrário.

O estudo do clima das cidades, por exemplo, teve um grande avanço quando dentre as teorias do Sistema Clima Urbano, propostas por Carlos Augusto de Figueiredo Monteiro (2009), foram apresentadas proposiçóes que destacavam os ventos em sua dialética com a produção do espaço urbano. Para o autor haveria canais de percepção do clima das cidades, dentre os quais o da qualidade do ar, denominado subsistema Físico-Químico, onde a ventilação urbana seria peça central para a difusão da poluição atmosférica, uma vez que "a ventilação, a partir de seus componentes intrassistêmicas tem o papel de difundir os poluentes" (MONTEIRO, op. cit., p. 52), e o subsistema Termodinâmico, que teria no vento uma das variáveis centrais para o cálculo do conforto térmico.

Monteiro (op. cit.) destaca ainda que a presença das ilhas de calor urbanas criaria um fluxo específico de ventilação porque formaria campos térmicos distintos, que, consequentemente, representariam novos gradientes de pressão atmosférica. E como "a geração da ilha de calor é suficiente para desencadear uma ventilação urbana, que 
se alterna com aquela local do quadro geoecológico e aquela mais ampla da circulação regional" (MONTEIRO, op. cit., p. 44), a compreensão da movimentação e dos fluxos correlacionando-os com os materiais que constituem o urbano são, portanto, fundamentais.

Partindo deste contexto, a seguir, será apresentada uma metodologia que foi utilizada para a proposiçáo deste ensaio sobre o estudo dos ventos, tendo uma cidade de porte médio e caracterizada por ter no relevo e padróes de cobertura da terra seus principais formadores de tipologias climáticas, como unidade territorial de estudo.

\section{PROCEDIMENTOS METODOLÓGICOS}

O propósito do trabalho foi estudar a relação que há entre os fluxos de velocidade e direção dos ventos em superfície na área central da cidade de Juiz de Fora, MG, dando ênfase aos componentes constituintes do urbano e o relevo local. Foram utilizadas bases cartográficas e alfanuméricas, coletadas e/ou produzidas em campo e em laboratório. A metodologia pôde ser dividida em quatro etapas: a) caracterização da área de estudo, b) escolha de pontos amostrais, c) Coleta e manuseio de dados, d) Síntese final.

\section{a) Caracterizaçáo da área de estudo}

Em primeiro lugar cabe aqui definir e caracterizar a base territorial que foi delimitada para o estudo. Neste teve-se maior atenção nas caracterizações gerais da área de estudo que levassem em conta as questóes ligadas ao parcelamento, uso e cobertura da terra, aos fatores morfológicos do relevo e aos processos sinóticos e elementos meteorológicos, pois são esses que irão influenciar na formação e fluxos dos ventos na cidade.

Juiz de Fora está localizada na zona da Mata mineira, no Sudeste do estado de Minas Gerais (figura 2). Possui uma área de $1.429,875 \mathrm{~km}^{2}$, quatro distritos (Juiz de Fora [sede], Torreóes, Rosário de Minas e Sarandira) e uma população de 516.247 habitantes (IBGE, 2010), sendo que 98,9\% deste total é população urbana, restando apenas 1,1 $\%$ de rural.

A cidade se destaca por ser um polo regional, atraindo pessoas de toda a regiáo da Zona da Mata, o que intensifica o fluxo de veículos automotores na região central da cidade. Nesse, mesmo havendo leis que buscam orientar o vetor de crescimento urbano para a região norte da cidade, em tentativa de atenuar os efeitos da urbanizaçáo e concentração desorganizada, ainda hoje possui uma movimentação diária intensa de lazer, negócios, trabalho e comércio, persistindo a concentração de pessoas, veículos, imóveis etc.

O que vem como consequência do fato de Juiz de Fora só ter conhecido uma legislação sobre o uso e ocupaçáo do solo urbano em 1986, com as leis 6908/86 que dispóem sobre o Parcelamento do Solo, a 6909/86, sobre o Código de Edificaçóes e a 6910/86, sobre o Ordenamento do Uso e Ocupação do Solo (TASCA, 2010). Foi somente nos anos 2000 que se concretizou a elaboração e aprovação de um plano diretor para a cidade. 
A cidade é dividida em 81 regiôes urbanas (termo concebido em 1989, através do Decreto do Executivo 04195/1989), caracterizadas por unidades menores e mais coesas, quanto às suas características, do que as unidades territoriais (UT's). Esta pesquisa abrangeu nove das regióes urbanas, as quais todas fazem limite com a região urbana Centro, estas são: Granbery, Jardim Glória, Jardim Paineiras, Jardim Santa Helena, Manoel Honório, Mariano Procópio, Morro da Glória, Nossa Senhora Aparecida e Poço Rio.

Em termos de caracterização ambiental, o município de Juiz de Fora se caracteriza por apresentar grandes variaçóes de altitudes, formação de inúmeros anfiteatros e planícies inter-montanas. Segundo Rocha (2005), a área municipal está situada sobre rochas variadas, com destaque para o Complexo Mantiqueira (norte) e o Complexo Juiz de Fora (Sudeste), e possui um relevo acidentado, com altitudes próximas a 1000 metros nos pontos mais elevados, 670 a 750 metros no fundo do vale do rio Paraibuna e níveis médios em torno de 800 metros. O mapeamento das feiçóes geomorfológicas de Juiz de Fora, realizado por Santiago (2008), permitiu constatar que cerca de $40 \%$ da área do município constitui-se de morros, caracterizados por um desnivelamento que varia de 100 a 200 metros, nos quais encontram-se feiçōes íngremes com topos convexos e, portanto, vales mais encaixados (SANTIAGO, 2008). 
Figura 2 - Localização do Município de Juiz de Fora-MG
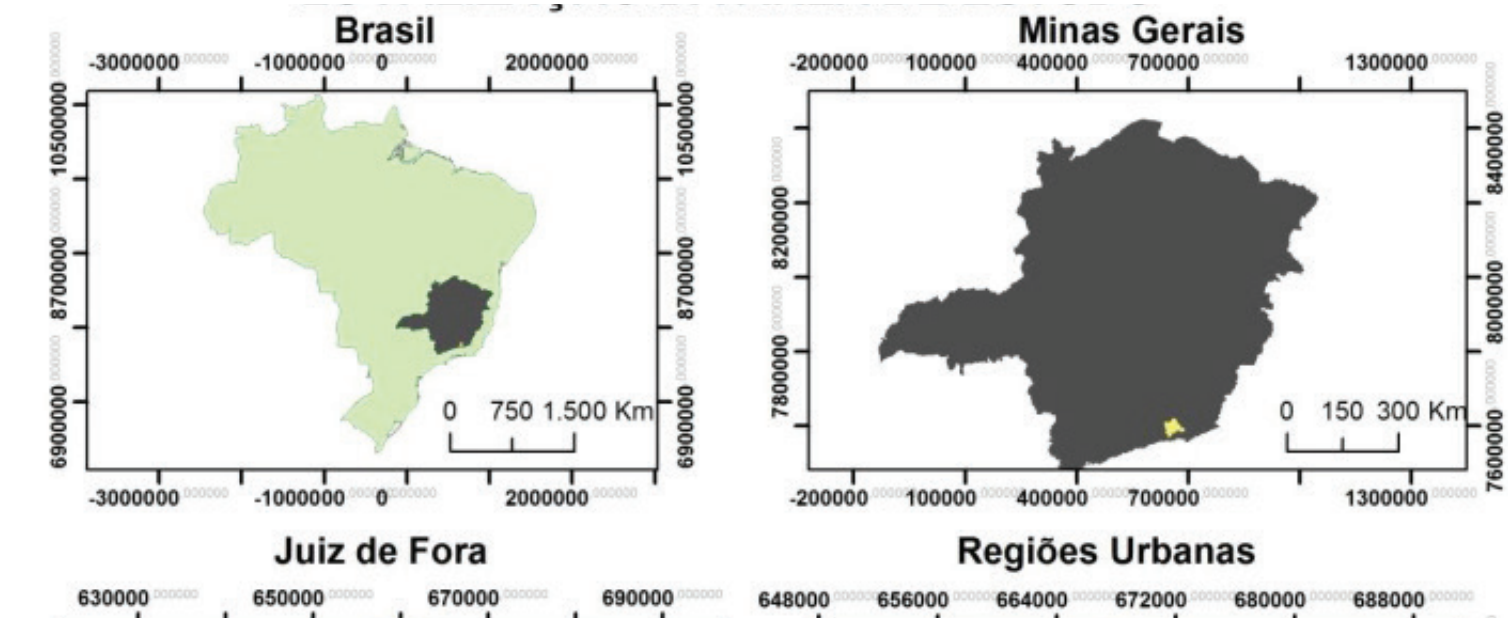

Regiōes Urbanas
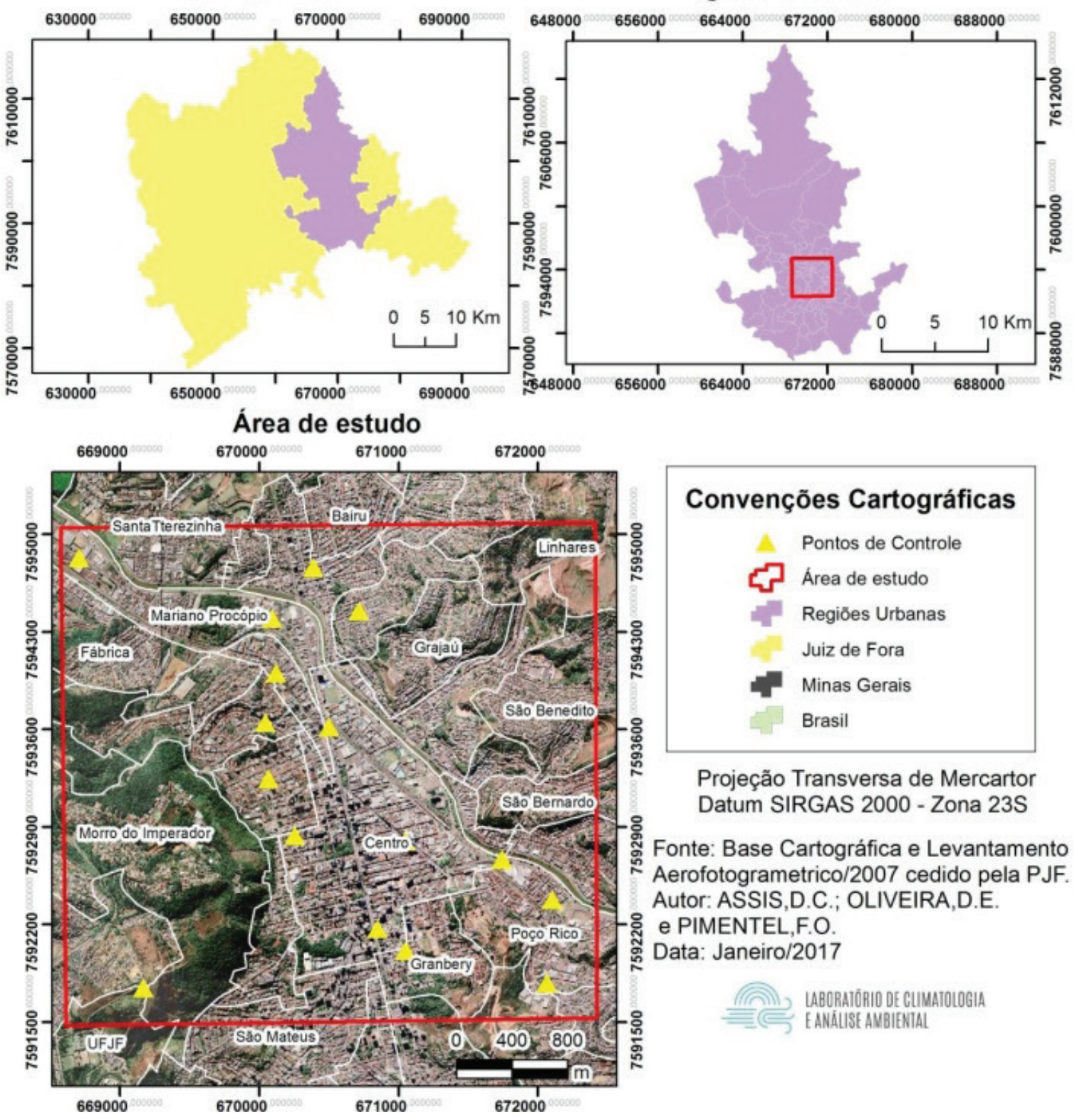

Fonte: os autores, 2017. 
Segundo Torres (2006, p. 162), “o clima de Juiz de Fora apresenta duas estações bem definidas: uma que vai de outubro a abril, com temperaturas mais elevadas e maiores precipitaçóes pluviométricas, e outra de maio a setembro, mais fria e com menor presença de chuvas". O período chuvoso concentra 83,9 \% das precipitaçóes, enquanto a estação seca, 16,1 \%. As temperaturas mais elevadas são registradas sob a ação da Massa Tropical Atlântica (mTa) e as mais baixas sob a ação da Massa Polar Atlântica (mPa).

Observando a série de dados de 1974 a 2014, verifica-se que a menor temperatura média no verão, registrada em 1974 , foi de $19,6{ }^{\circ} \mathrm{C}$ e a maior média foi registrada em 2014, com $22^{\circ} \mathrm{C}$ (LabCAA-UFJF, 2015). Já para o inverno, a menor média encontrada foi $16,32{ }^{\circ} \mathrm{C}$, no ano de 1989 , e a maior média foi $17,86{ }^{\circ} \mathrm{C}$, em 1995 . O maior total anual de precipitaçáo da série evidenciou o ano de 1997 como o mais seco, com um total acumulado de $641,7 \mathrm{~mm}$, e o de 1983 como o mais chuvoso, com 2265,5 mm. Ototal anual habitual variou entre 1342,2 a $1646,56 \mathrm{~mm}$.

O tipo climático da região é denominado como Tropical de Altitude, que corresponde a uma variaçáo do clima Tropical motivada pelas características do relevo regional, que é formado por altitudes médias à elevadas, que produzem um substancial arrefecimento das temperaturas. Segundo Brito (2013), a penetração dos ventos pelo litoral proporciona umidade nas vertentes a barlavento, como os presentes na Serra da Mantiqueira, contribuindo para a geração de "ilhas" úmidas nas vertentes de Leste e Sudeste. As ilhas úmidas, por sua vez, ao se associarem aos vales amplos e à turbulência do ar, contribuem para o surgimento de diversos topoclimas.

A partir dessas características e considerando que a cidade abriga uma populaçáo numerosa (516.247 habitantes, IBGE, 2010), é um polo regional e industrial, e ainda por possuir um relevo dissecado sob domínio de Mares de Morros (AB'SABER, 2003), que exerce influências nas tipologias de tempo, pôde-se passar para a etapa de descriçáo dos procedimentos metodológicos.

\section{b) Escolha de pontos amostrais}

Escolheu-se trabalhar com pontos amostrais, uma vez que havia a pretensão de alocar estaçôes meteorológicas portáteis em pontos específicos da área estudada. Optouse por aqueles que apresentariam características distintas e estivessem distribuídos espacialmente de forma a abranger uma maior área (figura 2). A escolha desses não foi arbitrária, uma vez que se pretendia identificar até que ponto as localidades com diferentes características formariam campos barométricos na cidade e a formação de ventos ou corredores de ventos.

Entende-se como ponto de controle o local onde a estação meteorológica foi alocada para coleta de dados em campo. Esses se dividem entre pontos fixos e itinerantes. Foram selecionados quatorze pontos.

Um dos pontos fixos estava localizado na rua Tiradentes, n. ${ }^{\circ 567}$, a 709 metros de altitude, e o outro no campus da Universidade Federal de Juiz de Fora, a uma altitude de 939,96 metros. O primeiro se encontra em um colégio particular da cidade e próximo 
a uma vegetaçáo arbórea espaçada à margem das vias de circulaçáo. O segundo em uma localidade com vegetação gramínea, próximo a uma área de mata.

Escolhidos os pontos e considerando as especificidades de cada um deles partiu-se para a etapa de coleta e construção de bases cartográficas e alfanuméricas.

\section{c) Coleta e manuseio de dados}

O primeiro dado a ser levantado foi o de campo, optando-se pela coleta das variáveis: velocidade e direção do vento e pressão atmosférica. Segundo Vianello e Alves (2012, p. 269):

o vento é representado pelo seu vetor velocidade, que, como tal, apresenta um módulo (ou intensidade), uma direção e um sentido, sua medição deverá fornecer estes três elementos. A intensidade do vento, no SI, é dada em metros por segundo. A direção e o sentido do vento são normalmente expressos em conjunto, tendose como referência o ponto cardeal de onde o vento se origina ou em graus, tornando-se como referência o ponto cardeal norte, girando-se no sentido horário (VIANELLO e ALVES, 2012, p. 269).

$\mathrm{Na}$ realização da coleta nos pontos itinerantes utilizou-se de duas estaçóes meteorológicas portáteis, modelo WNR928NX da marca Óregon, e ocorreu com o apoio de um Geógrafo, responsável técnico pela estação meteorológica do INMET alocada na Universidade Federal de (Juiz de Fora (UFJF), bolsistas de iniciação cientifica e equipamentos do Laboratório de Climatologia e Análise Ambiental (LabCAA) da UFJF.

As medições foram realizadas durante dez horas seguidas, sendo iniciadas às oito horas da manhã e encerradas às dezoito horas de cada dia. O intervalo adotado entre as mediçóes foi de quinze minutos, ou seja, de quinze em quinze minutos eram registrados os valores das variáveis. Destaca-se que, dada a disponibilidade de equipamentos, a coleta simultânea de dados se deu em dois pontos por dia, durante um período de sete dias (entre 11 e 19 de agosto de 2015). O sistema atmosférico que atuava na região em todos os dias estudados foi a massa Tropical Atlântica (Tabela 1), que é caracterizada pela estabilidade atmosférica. Nesses dias a pressão atmosférica variou entre 918,67 hPa a $911,21 \mathrm{hPa}$, a temperatura máxima foi de $25,6{ }^{\circ} \mathrm{C}$ (dia 19 de agosto) e a mínima de $12,4^{\circ} \mathrm{C}$ (dia 14 de agosto), e a umidade relativa média variou entre $65 \%$ dia 16 e 82 $\%$ dia 14.

Tabela 1 - Características dos dias de coleta.

\begin{tabular}{c|c|c|c|c|c|c|c|} 
Data & $\begin{array}{c}\text { Temp. } \\
\left({ }^{\circ} \mathbf{C}\right)\end{array}$ & Máx. $\left({ }^{\circ} \mathbf{C}\right)$ & Mín. $\left({ }^{\circ} \mathbf{C}\right)$ & $\begin{array}{c}\text { Umidade } \\
(\%)\end{array}$ & $\begin{array}{c}\text { Precipitação } \\
(\mathbf{m m})\end{array}$ & $\begin{array}{c}\text { Pressão } \\
(\mathbf{h P a})\end{array}$ & $\begin{array}{c}\text { Sistema } \\
\text { Atmosférico }\end{array}$ \\
\hline $11 / 08 / 2015$ & 15,14 & 20,5 & 12,6 & 79,5 & 0 & 918,67 & MTA \\
\hline $12 / 08 / 2015$ & 15,48 & 19,9 & 12,8 & 76,0 & 0 & 917,89 & MTA \\
\hline
\end{tabular}




\begin{tabular}{c|c|c|c|c|c|c|c|}
\hline Data & $\begin{array}{c}\text { Temp. } \\
\left({ }^{\circ} \mathbf{C}\right)\end{array}$ & Máx. $\left({ }^{\circ} \mathbf{C}\right)$ & Mín. $\left({ }^{\circ} \mathbf{C}\right)$ & $\begin{array}{c}\text { Umidade } \\
(\%)\end{array}$ & $\begin{array}{c}\text { Precipitação } \\
(\mathbf{m m})\end{array}$ & $\begin{array}{c}\text { Pressão } \\
(\mathbf{h P a})\end{array}$ & $\begin{array}{c}\text { Sistema } \\
\text { Atmosférico }\end{array}$ \\
\hline $13 / 08 / 2015$ & 16,53 & 22 & 12,7 & 74,1 & 0 & 917,84 & MTA \\
\hline $14 / 08 / 2015$ & 16,21 & 21,3 & 12,4 & 82,2 & 0 & 917,40 & MTA \\
\hline $15 / 08 / 2015$ & 17,11 & 22,7 & 13,2 & 76,3 & 0 & 916,92 & MTA \\
\hline $16 / 08 / 2015$ & 18,42 & 24,2 & 13,5 & 65,6 & 0 & 917,22 & MTA \\
\hline $17 / 08 / 2015$ & 17,43 & 23 & 13,8 & 77,0 & 0 & 917,28 & MTA \\
\hline $18 / 08 / 2015$ & 17,73 & 23,5 & 14 & 76,6 & 0 & 915,53 & MTA \\
\hline $19 / 08 / 2015$ & 19,43 & 25,6 & 14,7 & 73,4 & 0 & 911,21 & MTA \\
\hline
\end{tabular}

Fonte: Coletas em campo; INMET; Cartas sinóticas da Marinha do Brasil; Boletins Climanálise.

Assim, por estar sob atuação de uma mesma massa de ar, pôde-se considerar informações coletadas em dias diferentes, mas sempre as analisando em relação às informaçôes coletadas nos pontos fixos. Em tais pontos, a coleta dos dados se deu durante todos os dias estudados.

Em seguida, iniciou-se a tabulação dos dados coletados em campo, que permitiram que gráficos e mapas fossem feitos e que os principais sentidos e velocidades dos ventos fossem espacializados.

O mapa de "Fluxo dos ventos" foi elaborado considerando, temporalmente, três períodos de análise: 1) 08 h-09 h, 2) 13 h'-14 h horas e 3) 17 h-18 h horas. A escolha das classes se pautou no fato de que entre treze e quatorze horas há um maior aquecimento vertical do ar, o que poderia ocasionar o aumento na velocidade dos ventos (BARRY; CHORLEY, op. cit.). A partir da definição desse horário, optou-se em trabalhar com mais outros dois, que representariam o primeiro horário em que houve a possibilidade de haver coleta, a fim de constatar se as velocidades do vento tenderiam a ser menores perto do amanhecer (BARRY; CHORLEY, op. cit.), e o último horário de coleta ocorreu no período mais próximo ao entardecer. Três mapas foram realizados, um para cada um desses horários.

Por sua vez, as convenções cartográficas escolhidas para a simbologia desses mapas consideraram que o sentido de deslocamento do ar seria representado por setas nas direçóes cardeais e colaterais, e que a velocidade dos ventos seria marcada pelo gradiente de coloração das setas.

Ainda em relação ao fluxo dos ventos, com fins de observar a distribuição espacial na área de estudo, foram plotadas as informaçóes de velocidade e sentido dos ventos em um mapa que sintetiza todos os pontos. Nesse, considerou-se como dado a ser utilizado a maior velocidade registrada por ponto (independente do horário) e o sentido do vento predominante.

Após análise dos mapas, aferiu-se que o fluxo do vento seria condicionado, na área de estudo, principalmente pela altitude e altura das edificaçóes, o que acabou por 
orientar a proposição e elaboração de alguns materiais cartográficos, como a aquisição e tratamento dos dados do meio físico.

O procedimento de construção do mapa de "Altimetria da região central" consistiu na adição da camada de curvas de nível, com equidistância de cinco metros, no ambiente Arcmap. Em seguida, utilizou-se a ferramenta "TIN Create", do pacote de ferramentas "3D Analyst", o que gerou o modelo de altimetria através de modelagem por rede de triângulos irregulares.

As informações de altura das edificações, verificadas através da contagem de pavimentos de cada edificação, foi realizada através da ferramenta "Street View" do "Google Earth", e adicionando os dados à tabela de atributos da camada de lotes. Considerou-se que a altura de cada edificaçáo seria um valor aproximado, em que cada pavimento do edifício teria três metros de pé-direito e para cada loja com sobreloja cinco metros de pé direito, desconsiderando, portanto, a espessura de lajes e outras medidas. Este mapa permite observar náo apenas a altura dos edifícios, como também a largura e direcionamento das principais vias de acesso.

Todos os mapas foram realizados no software ArcGIS 10.

\section{d) Síntese final}

De posse dos mapas de Fluxo dos ventos, Altitude e Altura das edificaçóes iniciou-se o procedimento de síntese e consideraçôes finais.

\section{RESULTADOS}

Os resultados obtidos com os mapeamentos e gráficos permitiram aferir relações entre o relevo, a altura dos edifícios, a formação de campos barométricos e a dinâmica dos ventos. Optou-se por, primeiramente, fazer uma breve descrição das variáveis físicas, o que traria base para a compreensão dos fluxos de movimentação do ar.

Os padróes altimétricos encontrados demonstraram que grande parte da área de estudo encontra-se quase que predominantemente encaixada no vale do Rio Paraibuna, destacando apenas o ponto fixo da estação meteorológica do INMET, que está localizada na vertente com maior elevação da área de estudo, como é possível visualizar na figura 3. 
Figura 3 - Altimetria

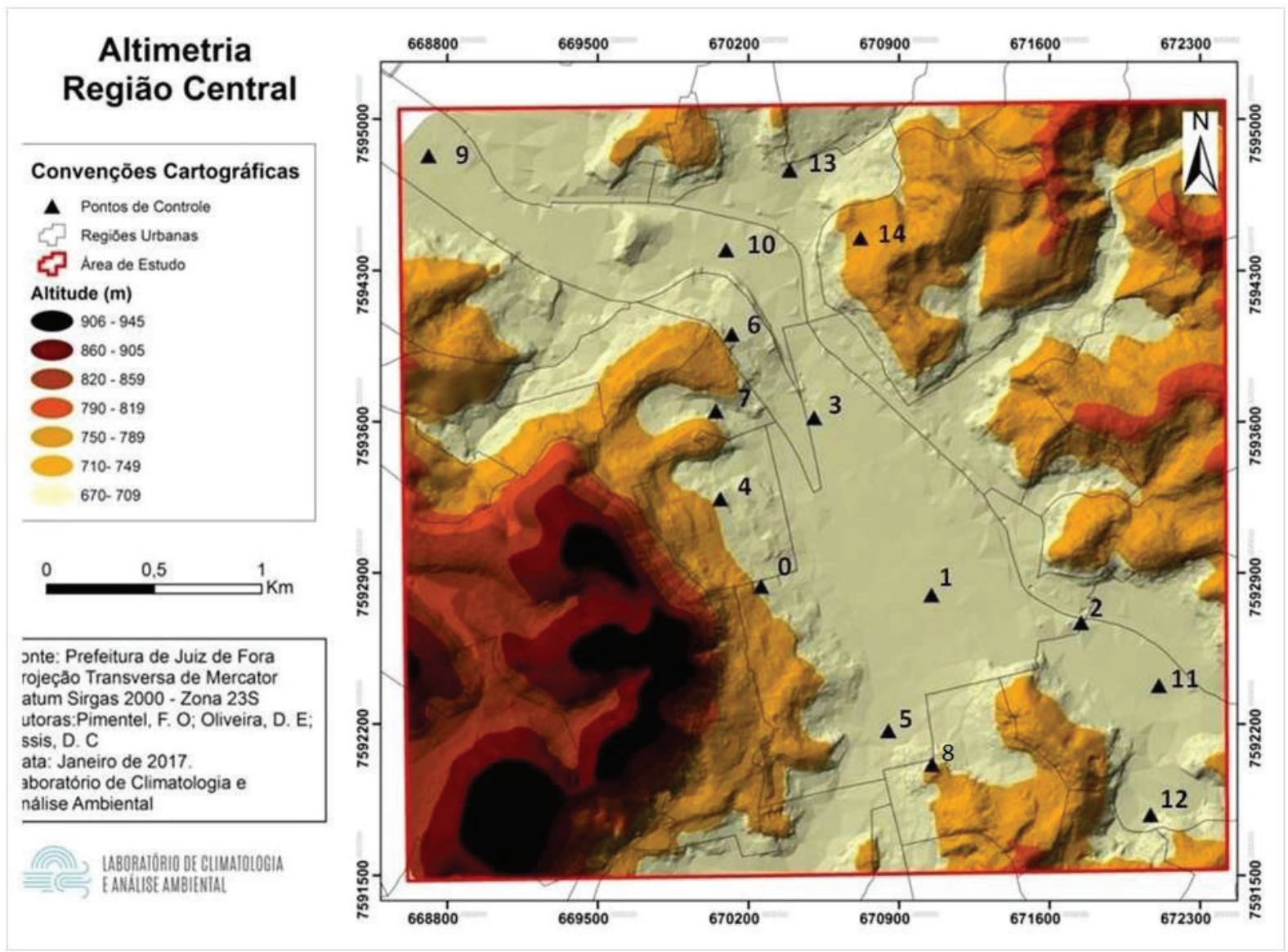

Fonte: Prefeitura de Juiz de Fora, 2017.

A variação altimétrica na área de estudo foi de 300 metros, sendo que a maior altitude encontrada foi de 940 metros na faixa Oeste da área, mais precisamente na regiáo que envolve a UFJF. Em contrapartida, nas proximidades da calha do Rio Paraibuna (a 640 metros de altitude) foram encontrados diversos pontos. Esta morfologia do relevo pode influenciar na velocidade e direção dos ventos, pois as correntes de vento diminuem a velocidade quando entram em contato com as rugosidades da superfície.

Este é um dos principais fatores que pode estar influenciando na dinâmica dos ventos registrados no ponto fixo da Estação meteorológica do INMET. A partir do mapa de altimetria e dos dados coletados em superfície pode-se identificá-lo como uma excepcionalidade frente aos demais, apresentando registros de maior velocidade do vento. $\mathrm{O}$ fato de estar localizado livre das barreiras geradas pelas edificaçóes (figura 4), dada a sua maior altitude, e localizado no topo de um morro, diminui os impactos que sofreria em relação à superfície. 
Figura 4 - Altura das edificações

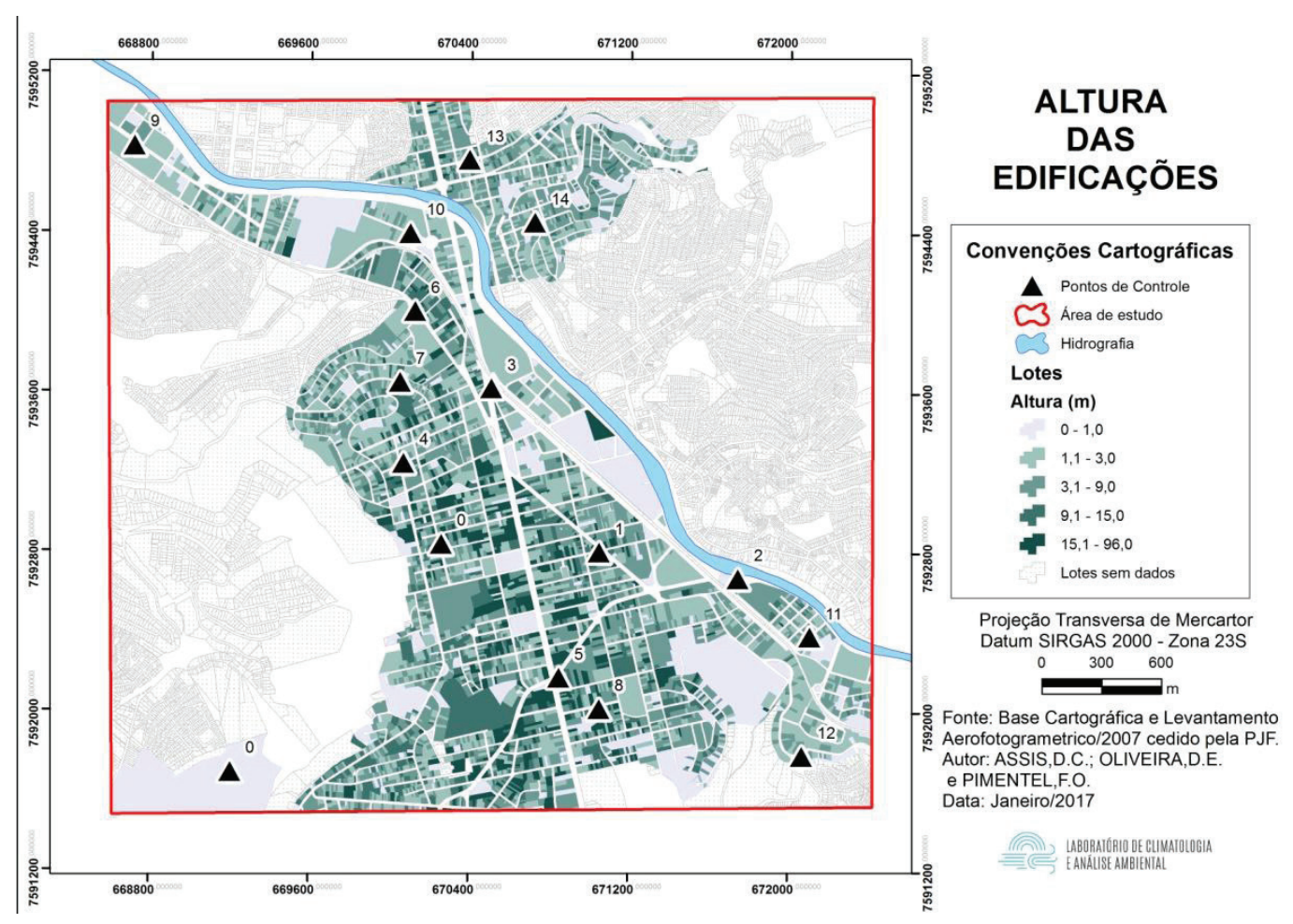

Fonte: os autores, 2017.

Os outros pontos estão localizados no vale do rio Paraibuna e podem estar sob influência da altura das edificaçóes (figura 4), uma vez que a RU Centro e em menor proporção a RU Granbery apresentam edificações de alturas elevadas (entre 15 e 96 metros), que se destacam frente às demais, pois indicaram uma verticalidade maior presente na região. Nestas, haveria a possibilidade de formação de canyons urbanos, que poderiam ser os responsáveis pela criação de corredores de ventos e a formaçáo de ventos locais.

A área no entorno do ponto 8, por exemplo, é cercada por edificaçóes elevadas, o que pode revelar alguma relaçáo com os elevados valores de velocidade do vento registrados nesse, destacando a influência dos corredores de vento. Segundo Mascaró (2002), o fenômeno de canalização do vento ocorre de forma mais significativa quando a calha é bem definida e estreita, apresentando largura 2,5 vezes menor que a sua, porém os efeitos são incômodos apenas quando a velocidade do vento ultrapassa $3,5 \mathrm{~m} / \mathrm{s}$. Em nenhum momento no ponto de controle 8 esse limite foi ultrapassado nos registros encontrados, mas como foi considerado apenas dados de velocidade média, poderiam assim ter havido rajadas que superaram esse valor.

Os dias estudados apresentaram constância na velocidade dos ventos, prevalecendo as rajadas de até $3 \mathrm{~m} / \mathrm{s}$ na regiáo baixa da cidade (próximo aos setecentos metros) e de até $6 \mathrm{~m} / \mathrm{s}$ no ponto da UFJF, que se localiza a uma altitude de 940 metros. Para os 
pontos fixos a velocidade dos ventos variou entre 0 (ou ausência de ventos) e $6,3 \mathrm{~m} / \mathrm{s}$, e a direção predominante nesses dois pontos foi de Sudoeste no ponto fixo do colégio CAVE e Sudeste no ponto fixo UFJF. Por sua vez, nos pontos móveis prevaleceram no geral as velocidades menores que $2 \mathrm{~m} / \mathrm{s}$ e o sentido dos ventos foi o Leste e o Nordeste.

Tabela 2 - Velocidade e direção do vento em pontos fixos.

\begin{tabular}{|c|c|c|c|c|c|c|c|c|c|c|c|c|}
\hline \multirow{3}{*}{ Data } & \multicolumn{6}{|c|}{ Ponto Fixo - CAVE } & \multicolumn{6}{|c|}{ Ponto Fixo - UFJF } \\
\hline & \multicolumn{2}{|c|}{ Periodo 1} & \multicolumn{2}{|c|}{ Periodo 2} & \multicolumn{2}{|c|}{ Periodo 3} & \multicolumn{2}{|c|}{ Periodo 1} & \multicolumn{2}{|c|}{ Periodo 2} & \multicolumn{2}{|c|}{ Periodo 3} \\
\hline & Vel. & Dir. & Vel. & Dir. & Vel. & Dir. & Vel. & Dir. & Vel. & Dir. & Vel. & Dir. \\
\hline $11 / 08 / 2015$ & 2,2 & $S$ & 3,8 & SE & 2,7 & NW & 4 & SE & 1,6 & $E$ & 2,8 & SE \\
\hline $12 / 08 / 2015$ & 2,5 & S & 6,3 & SE & 2,7 & NE & 1,6 & $E$ & 3 & SE & 3,5 & SE \\
\hline 13/08/2015 & 2,9 & S & 3,4 & SW & 2,2 & SW & 2,3 & NE & 3,1 & $E$ & 3,2 & SE \\
\hline $14 / 08 / 2015$ & 0 & SW & 2,7 & SW & 0 & NW & 0,4 & NE & 4 & SE & 3,8 & SE \\
\hline $15 / 08 / 2015$ & 0 & NW & 0 & NW & 0 & NW & 2,6 & NE & 2,6 & SE & 2,8 & SE \\
\hline 16/08/2015 & 0 & NW & 0 & NW & 0 & NW & 2,9 & NE & 4,8 & SE & 3 & SE \\
\hline $17 / 08 / 2015$ & 2 & SW & 2,1 & $E$ & 2,9 & NW & 0 & $\mathrm{NE}$ & 3,1 & SE & 4,6 & SE \\
\hline $18 / 08 / 2015$ & 0 & SW & 2,2 & SW & 3,3 & NW & 2,6 & $E$ & 3,4 & $E$ & 3,9 & SE \\
\hline 19/08/2015 & 2,7 & SW & 1,9 & SW & 1,6 & SW & 2,7 & $\mathrm{NE}$ & 2,2 & $E$ & 3,3 & $E$ \\
\hline
\end{tabular}

Fonte: Coleta em campo; INMET.

Tabela 3. Velocidade e direção do vento em pontos móveis.

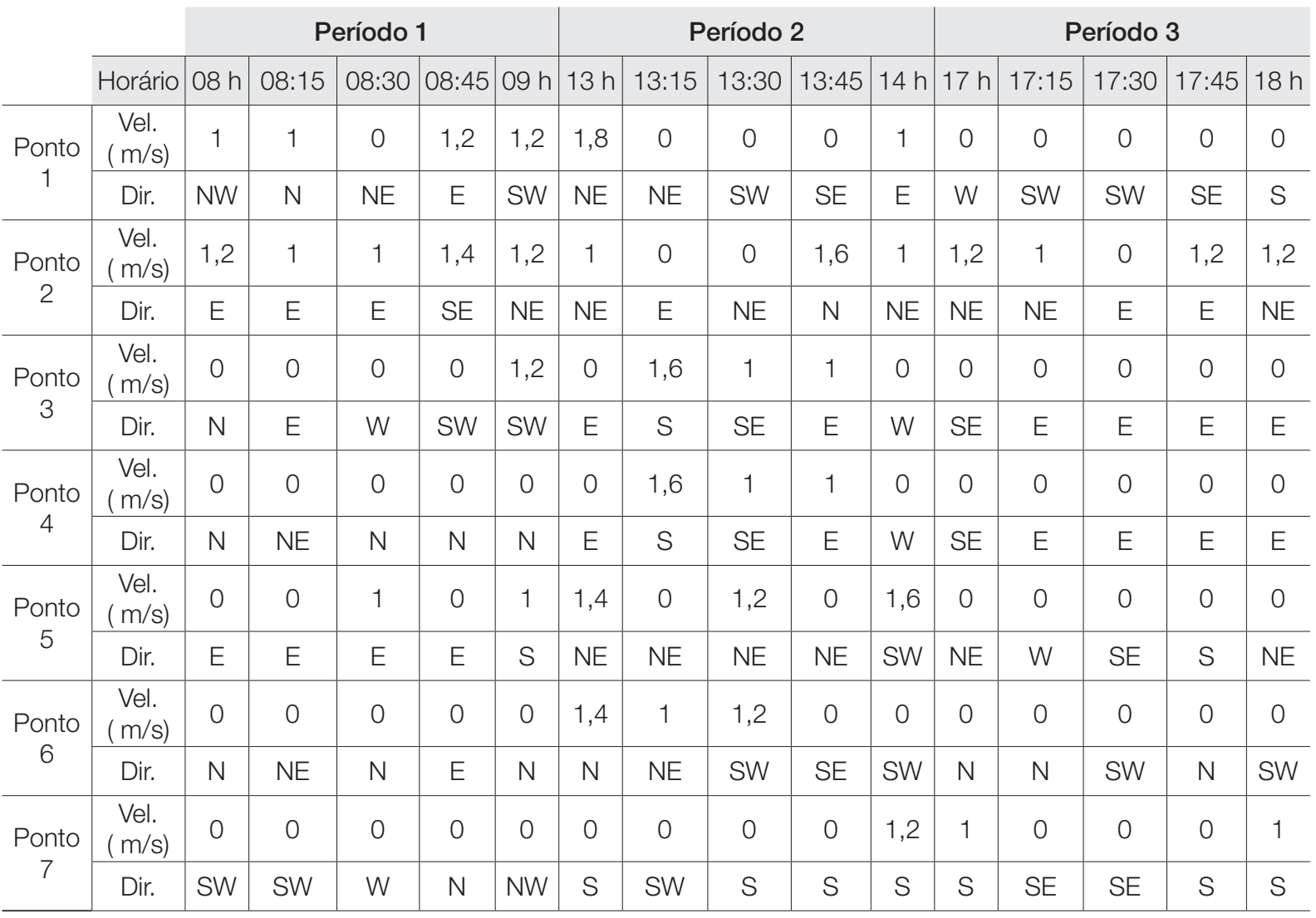




\begin{tabular}{|c|c|c|c|c|c|c|c|c|c|c|c|c|c|c|c|c|}
\hline & \multirow[b]{2}{*}{ Horário } & \multicolumn{5}{|c|}{ Período 1} & \multicolumn{5}{|c|}{ Período 2} & \multicolumn{5}{|c|}{ Período 3} \\
\hline & & $08 \mathrm{~h}$ & 08:15 & $08: 30$ & 08:45 & $09 \mathrm{~h}$ & $13 \mathrm{~h}$ & $13: 15$ & $13: 30$ & $13: 45$ & $14 \mathrm{~h}$ & $17 \mathrm{~h}$ & $17: 15$ & $17: 30$ & $17: 45$ & $18 \mathrm{~h}$ \\
\hline \multirow{2}{*}{$\begin{array}{c}\text { Ponto } \\
8\end{array}$} & $\begin{array}{l}\text { Vel. } \\
(\mathrm{m} / \mathrm{s})\end{array}$ & 1,2 & 1 & 1,2 & 0 & 1,4 & 2,4 & 1,6 & 2,6 & 3,4 & 1,2 & 1,6 & 2,8 & 2,2 & 1,8 & 2,4 \\
\hline & Dir. & E & $E$ & $E$ & $E$ & $E$ & E & E & E & $E$ & E & $E$ & $E$ & $E$ & $E$ & $E$ \\
\hline \multirow{2}{*}{$\begin{array}{c}\text { Ponto } \\
9\end{array}$} & $\begin{array}{c}\text { Vel. } \\
(\mathrm{m} / \mathrm{s})\end{array}$ & 2,6 & 1,8 & 2,4 & 1,4 & 1,2 & 2,8 & 1,2 & 2,4 & 2,8 & 1,6 & 1,4 & 0 & 1,2 & 1,4 & 1,8 \\
\hline & Dir. & $\mathrm{N}$ & $\mathrm{N}$ & $\mathrm{N}$ & $\mathrm{N}$ & $\mathrm{N}$ & $\mathrm{N}$ & SW & S & S & $\mathrm{N}$ & E & $E$ & $\mathrm{~N}$ & E & $E$ \\
\hline \multirow{2}{*}{$\begin{array}{c}\text { Ponto } \\
10\end{array}$} & $\begin{array}{c}\text { Vel. } \\
(\mathrm{m} / \mathrm{s})\end{array}$ & 0 & 0 & 0 & 0 & 1,2 & 2,4 & 1,4 & 1,6 & 1,2 & 1,4 & 0 & 1,8 & 1,2 & 0 & 0 \\
\hline & Dir. & NE & $N$ & $N$ & $\mathrm{~N}$ & $N$ & E & E & SW & SE & S & $S$ & S & SW & $S$ & SE \\
\hline \multirow{2}{*}{$\begin{array}{c}\text { Ponto } \\
11\end{array}$} & $\begin{array}{c}\text { Vel. } \\
(\mathrm{m} / \mathrm{s})\end{array}$ & 0 & 0 & 1,6 & 0 & 0 & 1,4 & 1,2 & 0 & 1,8 & 1,2 & 1,6 & 1 & 0 & 1 & 0 \\
\hline & Dir. & NE & W & $\mathrm{NE}$ & NE & SW & SW & $\mathrm{NE}$ & SW & NE & $N E$ & $\mathrm{~N}$ & NE & W & SW & W \\
\hline \multirow{2}{*}{$\begin{array}{c}\text { Ponto } \\
12\end{array}$} & $\begin{array}{l}\text { Vel. } \\
(\mathrm{m} / \mathrm{s})\end{array}$ & 1,2 & 0 & 1,6 & 1,8 & 1,4 & 1,4 & 1,8 & 2,2 & 1,2 & 2,6 & 1,2 & 1,4 & 1,8 & 0 & 1,2 \\
\hline & Dir. & SW & $E$ & SE & SE & NE & NW & E & E & E & E & NE & $E$ & E & E & NW \\
\hline \multirow{2}{*}{$\begin{array}{c}\text { Ponto } \\
13\end{array}$} & $\begin{array}{l}\text { Vel. } \\
(\mathrm{m} / \mathrm{s})\end{array}$ & 2,6 & 1,4 & 1,2 & 1,8 & 0 & 1,4 & 1,4 & 1,2 & 1 & 0 & 1,8 & 1 & 1,4 & 0 & 0 \\
\hline & Dir. & $E$ & SW & SE & $E$ & SW & E & E & SE & W & E & SE & SE & E & SE & $E$ \\
\hline \multirow{2}{*}{$\begin{array}{c}\text { Ponto } \\
14\end{array}$} & $\begin{array}{c}\text { Vel. } \\
(\mathrm{m} / \mathrm{s})\end{array}$ & 1 & 1,4 & 1,4 & 1,2 & 0 & 1,2 & 1 & 2,2 & 2,2 & 1,8 & 2,2 & 0 & 0 & 1 & 0 \\
\hline & Dir. & $E$ & $E$ & $E$ & $\mathrm{NE}$ & $\mathrm{NE}$ & $\mathrm{NE}$ & $\mathrm{NE}$ & $\mathrm{NE}$ & E & $\mathrm{NE}$ & $\mathrm{NE}$ & $\mathrm{NE}$ & E & E & $\mathrm{NE}$ \\
\hline
\end{tabular}

Fonte: Coleta em campo, (2015).

Sobre os fluxos dos ventos (figuras 5, 6, 7 e 8), os dados revelaram que existe uma conformidade com relação à velocidade do vento, ou seja, observa-se que os diferentes pontos apresentaram valores muito próximos dentro dos períodos determinados para a análise. E que foi recorrente o registro de velocidades inferiores a $2 \mathrm{~m} / \mathrm{s}$ nos pontos de controle itinerantes, como pode ser observado na figura 5.

O primeiro ponto itinerante, "Ponto 1", foi instalado na rua Halfeld, que se caracteriza por estar situada em um local completamente impermeabilizado, edificado e com grande fluxo de pessoas e veículos automotores. Esse ponto de controle foi alocado mais precisamente no cruzamento entre o calçadáo da rua Halfeld e a avenida Getúlio Vargas, a 677 metros de altitude. Neste ponto a orientaçáo do vento no primeiro e segundo período foi para NW, acompanhando o sentido da disposição da via avenida Getúlio Vargas, e com velocidade entre 1 e $2 \mathrm{~m} / \mathrm{s}$ nos dois momentos. Já no terceiro período, de 17 às 18 horas da tarde, registra-se calmaria e o direcionamento SW. 
Figura 5 - Fluxo dos ventos: Velocidade e sentido (08:00-09 h)
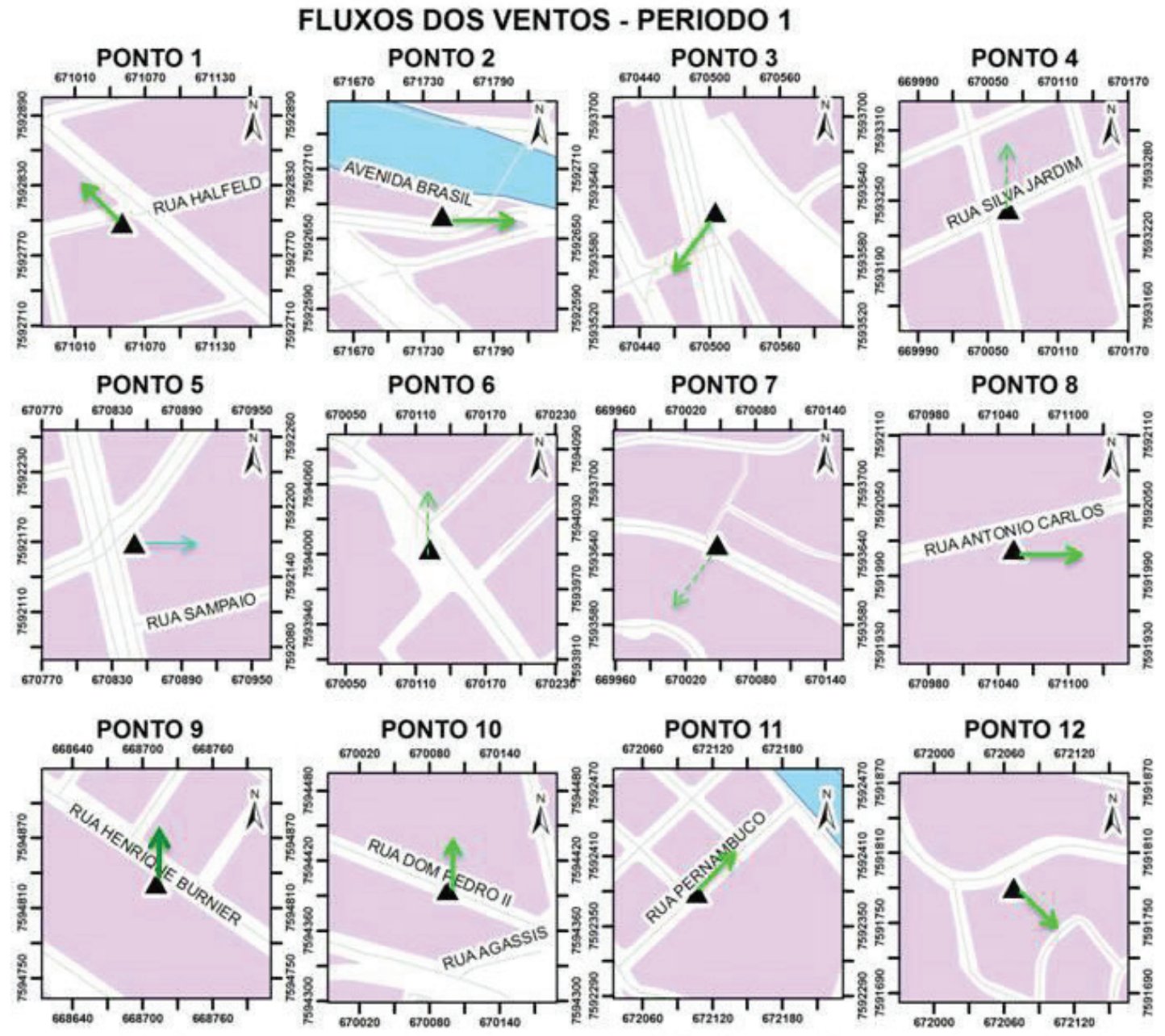

PONTO 12

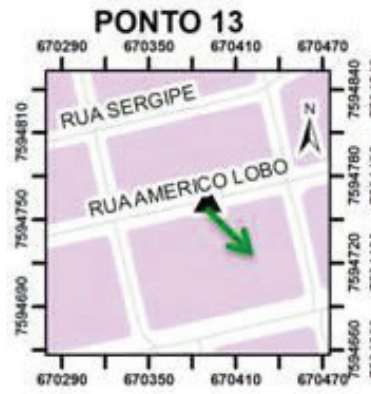

PONTO 14

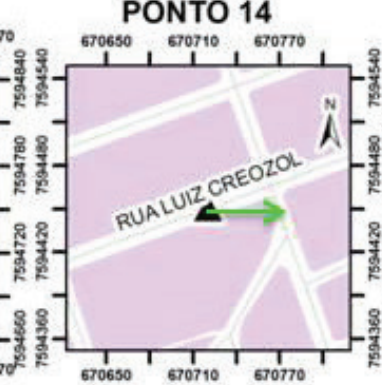

PONTO FIXO - CAVE

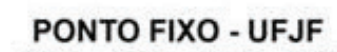

Convençōes Cartográficas

A Pontos de controle Arruamento

147 Quadras

C. Área de estudo

3 Rio Paraibuna
Velocidade do Vento

$(\mathrm{m} / \mathrm{s})$

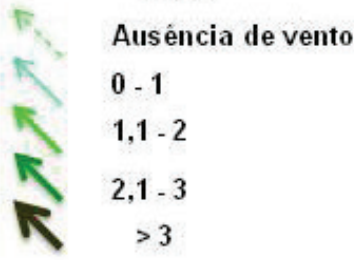

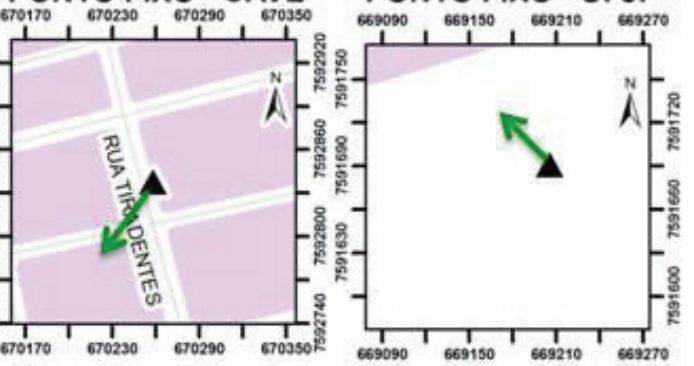

Projeção Transversa de Mercartor Datum SIRGAS 2000 - Zona 23S

$$
\begin{aligned}
& \text { Fonte: Base Cartográfica cedido } \\
& \text { pela PJF e dados de campo. } \\
& \text { Autor: ASSIS,D.C.; OLIVEIRA,D.E. } \\
& \text { e PIMENTEL,F.O. } \\
& \text { Data: Janeiro/2017 }
\end{aligned}
$$

LABOBAIORIO DE CIIMATULOGLA EANALISE ANBIENTAL 
O segundo ponto de controle encontra-se também a 677 metros de altitude, entre a avenida Brasil e a rua Espírito Santo a apenas alguns metros da calha do rio Paraibuna (à margem direita), possuindo alguns exemplares de vegetação arbórea e grande circulação de veículos, inclusive veículos pesados. Nos registros, no primeiro momento, é verificado o vento no sentido E, com velocidade entre 1 e $2 \mathrm{~m} / \mathrm{s}$, já no segundo e terceiro período do dia, mantém-se a velocidade dentro da mesma classe, porém muda-se o sentido o qual destaca-se na direçáo NE nos dois últimos intervalos.

O Ponto 3 está a 676 metros de altitude e localiza-se na avenida Barão do Rio Branco, que é a principal via de circulação da região central, sendo expressiva em seu tamanho e largura, cercada por edificaçóes de elevações consideráveis, como pode ser observado no mapa de altura das edificaçóes. A velocidade do vento nesse ponto manteve-se entre 1 e $2 \mathrm{~m} / \mathrm{s}$ nos dois primeiros intervalos, variando apenas o sentido, sendo no primeiro momento predominantemente SW e no segundo no sentido E, no último intervalo observou-se calmaria, com direçáo E.

Já o ponto 4, localiza-se na regiáo urbana do Jardim de Santa Helena, exatamente na rua Silva Jardim, quase esquina com a rua Olegário Maciel, a 705 metros de altitude. A área caracteriza-se pela presença de edificaçóes do tipo casa, ou seja, menos elevadas, e algumas árvores nas calçadas. Nessa localidade foi marcado no primeiro e no terceiro período calmaria, com direcionamento voltado para $\mathrm{N}$ e E, respectivamente. Porém, no período 2, verificou-se velocidade entre 1 e $2 \mathrm{~m} / \mathrm{s}$ no sentido E.

O ponto 5 alocado a 682 metros de altitude, configura-se em um dos principais cruzamentos da regiáo central, o encontro da avenida Baráo do Rio Branco com a avenida Itamar Franco que concentra um altíssimo fluxo de veículos e pessoas. A área que contorna o ponto possui inúmeras edificaçóes de alturas mais elevadas com um alto grau de impermeabilização, ou seja, sem a presença de arborização. Nesse ponto registraram-se velocidades do vento mais baixas e até mesmo ausentes. No primeiro momento a velocidade do vento estava entre 0 e $1 \mathrm{~m} / \mathrm{s}$, no sentido Leste, em seguida no período 2 viu-se um aumento da velocidade para a classe de 1 a $2 \mathrm{~m} / \mathrm{s}$, da direção $\mathrm{NE}$, paralela ao sentido da avenida Itamar Franco. Por fim, no final do dia, registrouse calmaria, com sentido SE. 
Figura 6 - Fluxo dos ventos: Velocidade e sentido (13 h-14 h)
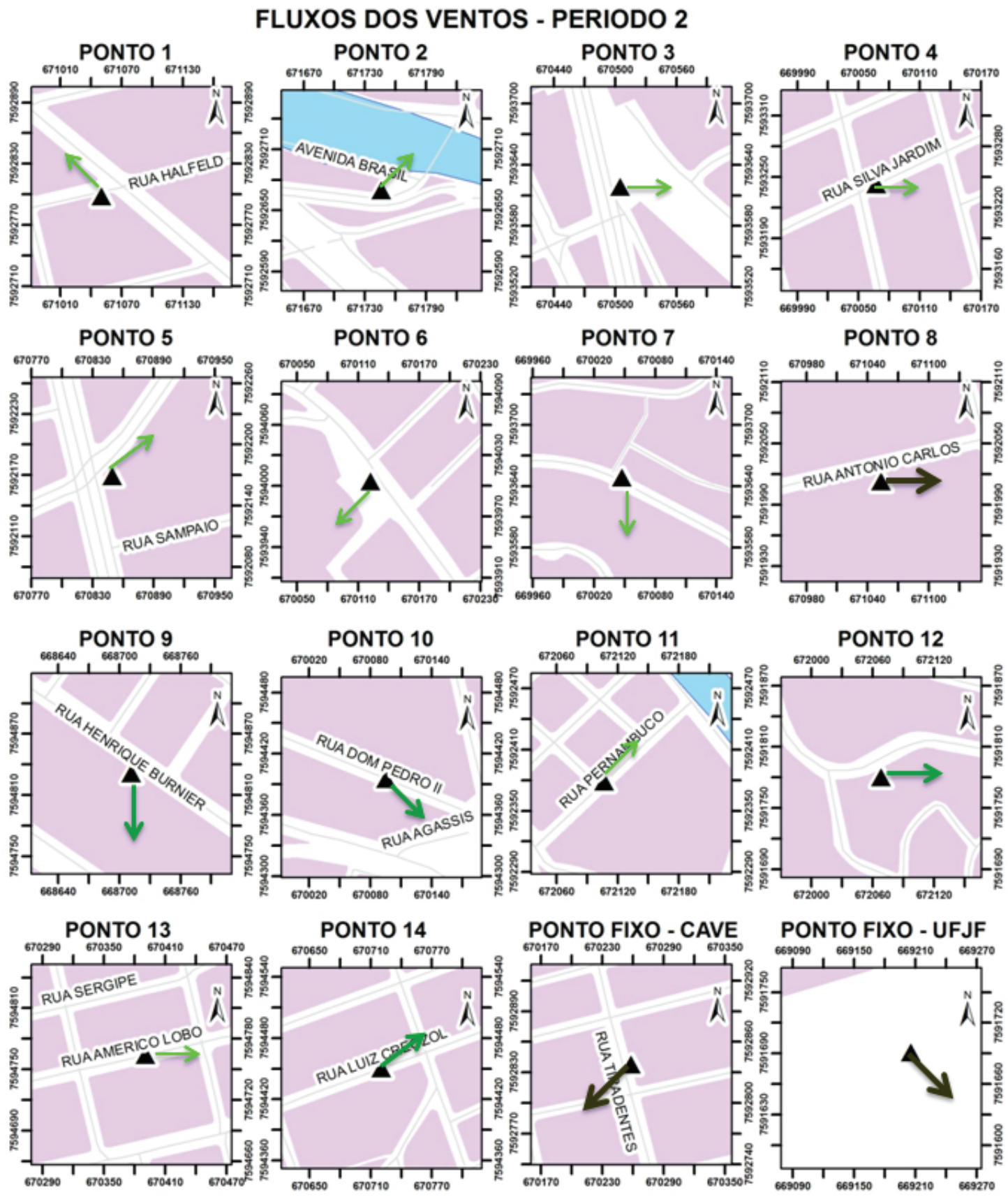

Convençőes Cartográficas

A Pontos de controle Arruamento Quadras

Área de estudo

3 Rio Paraibuna
Velocidade do Vento $(\mathrm{m} / \mathrm{s})$

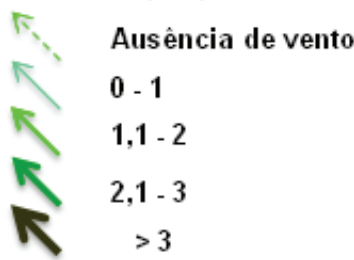

Projeção Transversa de Mercartor Datum SIRGAS 2000 - Zona 23S

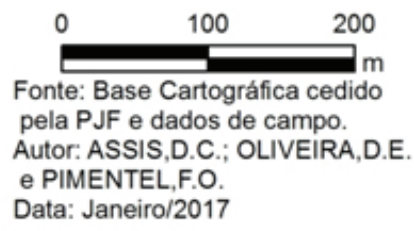

LABORATÓRIO OE CIIMATOLOGIA EANÁLISE ANBIENTAL

Fonte: os autores, (2017) 
O ponto 6 se diferencia do ponto anterior devido, primeiramente a altitude, já que este encontra-se a 705 metros de altitude, e porque, apesar de também se localizar em uma importante via de circulação, neste ponto tem-se a presença de vegetação arbórea e de edificaçôes não táo expressivas. Os dados coletados nesse ponto revelam uma situação de calmaria tanto no primeiro período quanto no segundo, com direcionamento $\mathrm{N}$, apenas no período 2, que já possui tendência a ventos com maiores velocidades, uma vez que nesse tiveram registros de vento com velocidade entre 1 a $2 \mathrm{~m} / \mathrm{s}$, com direcionamento no sentido SW.

O ponto 7, instalado na rua Dr. João Pinheiro, em frente ao número 264, a 690 metros de altitude, possui uma característica diferenciada diante dos demais pontos apresentados anteriormente, pois possui um perfil mais residencial. O seu entorno é marcado por edificaçóes não muito elevadas, variando entre casas e prédios de até três pavimentos, demonstrando assim um caráter mais horizontalizado da região urbana do Jardim Glória, como pode ser visualizado na figura 4. O primeiro momento foi marcado por registros de calmaria e a direção predominante de SW; seguida, no período entre treze e quatorze horas de ventos com velocidade entre 1 e $2 \mathrm{~m} / \mathrm{s}$ no sentido Sul; e ao entardecer uma queda na velocidade, sendo registrada a classe de 0 a $1 \mathrm{~m} / \mathrm{s}$, no mesmo sentido do período anterior.

O ponto de controle 8 foi alocado na rua Antônio Carlos, em frente ao edifício de n. ${ }^{\circ} 347$, a 708 metros de altitude. A área se caracteriza por uma presença representativa de novas edificações, mais elevadas e de alto padrão. Este ponto foi destacado anteriormente devido aos elevados valores de velocidade verificados, o sentido foi predominantemente $\mathrm{E}$ em todos, variando apenas a intensidade dos ventos. A velocidade máxima registrada nesse ponto foi de $3,4 \mathrm{~m} / \mathrm{s}$, no horário das $13 \mathrm{~h} 45 \mathrm{~min}$.

Em relação ao ponto de controle de número 9, localizado na rua Henrique Burnier, em frente à fábrica da "Coca-Cola”, acomodado entre inúmeros galpóes em uma via de alto fluxo de veículos leves e pesados e nas proximidades do Rio Paraibuna, caracterizase por ventos com intensidades mais elevadas, no sentido norte, com velocidades entre 2,1 a $3 \mathrm{~m} / \mathrm{s}$, no horário de treze às quatorze horas mantém-se força dos ventos, porém alterna-se o sentido para Sul. Enfim, no final da tarde, tem-se a reduçáo da intensidade do vento para a classe de 1,1 a $2,0 \mathrm{~m} / \mathrm{s}$, mas agora no sentido Leste.

O ponto 10 está localizado na rua D. Pedro II, atrás da sede do Clube de Tênis D. Pedro II, a 677 metros de altitude, em uma via pouco movimentada e com edificaçóes do tipo casa ou pequenos prédios, como é possível visualizar na figura 4 . Os ventos nesse ponto acompanharam o sentido norte-sul, estavam em calmaria na primeira hora de medição (entre $08 \mathrm{~h}$ e 09 h horas) e no final da tarde. Continuou em calmaria até as $08 \mathrm{~h} 45 \mathrm{~min}$ e entre $09 \mathrm{~h}$ e $14 \mathrm{~h}$ horas foram registrados ventos de até $2,4 \mathrm{~m} / \mathrm{s}$ (medição de $13 \mathrm{~h}$ ).

O ponto 11 foi instalado na rua Pernambuco, próximo à casa de n. ${ }^{\circ} 115$, a 675 metros de altitude, em uma via de baixo fluxo de pessoas e veículos, sem presença de vegetação arbórea e as edificaçóes variaram de pequenas casas a edifícios com poucos 
pavimentos. Nesse ponto o sentido dos ventos foi de Sudoeste e Nordeste, acompanhando a disposição linear da rua. A velocidade média dos ventos registrados nesse ponto foi de $0,7 \mathrm{~m} / \mathrm{s}$, sendo o maior registro o das $13 \mathrm{~h} 45 \mathrm{~min}$.

O ponto 12 foi alocado na rua Francisco Valadares, em frente ao supermercado Bahamas, a 678 metros de altitude. Esse ponto apresenta um maior fluxo de veículos, já que se trata de uma via que interliga várias regióes da cidade ao centro. Através da visita em campo é notável que a região no entorno do ponto caracteriza-se por alguns galpóes de distribuição e pequenas fábricas, dividindo espaço com uma pequena parcela de unidades de uso residencial. Nesse ponto a direção predominante é de Sudeste e Leste. A velocidade média dos ventos no primeiro período de contagem foi de $1,2 \mathrm{~m} / \mathrm{s}$, seguida de $1,84 \mathrm{~m} / \mathrm{s}$ no segundo e 1,12 no terceiro.

O ponto 13 foi alocado na avenida Américo Lobo em frente ao edifício de n. ${ }^{\circ} 1107$. Esse ponto localiza-se em uma importante regiáo da zona Nordeste, devido à sua funcionalidade para as demais regióes no entorno, oferecendo possibilidades de comércio e serviços. $\mathrm{Na}$ avenida onde o ponto foi acomodado verifica-se um alto fluxo de veículos leves e pesados durante todo o dia, apresentando pontos de congestionamentos em alguns momentos do dia. Localizado a 682 metros de altitude, tal ponto teve como direção predominante a Sudeste, Sudoeste e um registro de ventos pela manhá que chegaram aos $2,6 \mathrm{~m} / \mathrm{s}$.

O último ponto (14) foi alojado à frente do número 165 da rua Luiz Creozol, uma via que não possui um fluxo considerável de veículos em relação às ruas de maior circulação na região urbana de Nossa Senhora Aparecida. Esse ponto pertence a uma regiáo de exemplares de edificaçóes mais simples e até mesmo mais precários, sendo essencialmente residencial. Também localizado em uma área de altitude mais elevada (724 metros) que o vale, pode ter nisso a explicação para que a predominância dos ventos em todos os horários seja de Nordeste. Nesse caso, também deve-se considerar o fato de que o sentido do vento indica ainda que está saindo de uma área mais ocupada e verticalizada, que pode estar dispersando os ventos até ele. Os registros indicaram ventos que chegaram aos 2,2 m/s, nos horários de $13 \mathrm{~h} 30 \mathrm{~min}, 13 \mathrm{~h} 45 \mathrm{~min}$ e $17 \mathrm{~h}$ horas, e a média do dia foi de $1,1 \mathrm{~m} / \mathrm{s}$. 
Figura 7 - Fluxo dos ventos: Velocidade e sentido (17 h-18 h)
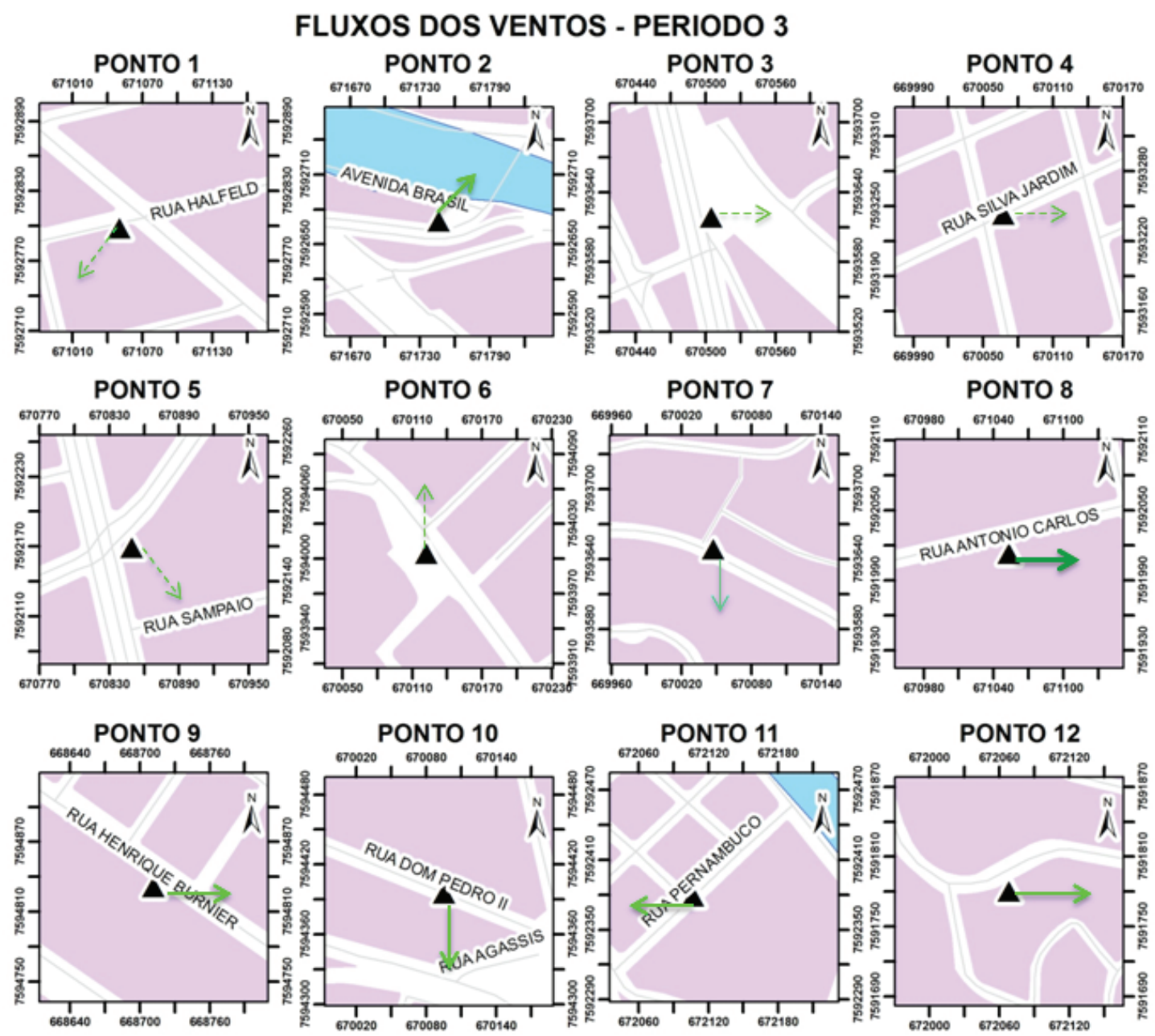

PONTO 12
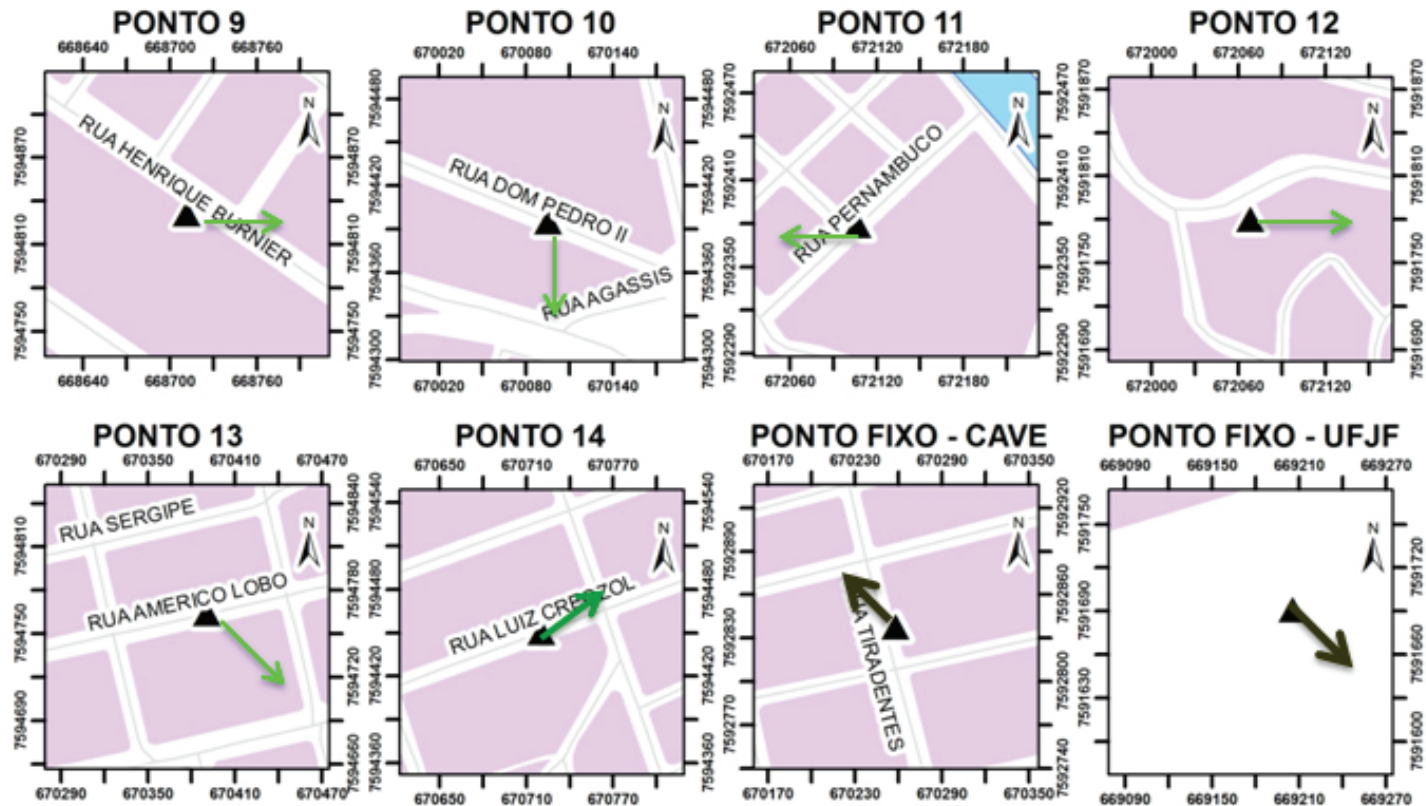

\section{Convençōes Cartográficas}

A Pontos de controle

Arruamento

Quadras

5. Area de estudo

$\checkmark 3$ Rio Paraibuna
Velocidade do Vento

$(\mathrm{m} / \mathrm{s})$

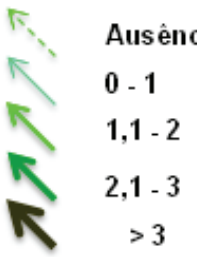

Projeção Transversa de Mercartor Datum SIRGAS 2000 - Zona 23S

$$
\begin{aligned}
& \text { Fonte: Base Cartográfica cedido } \\
& \text { pela PJF e dados de campo. } \\
& \text { Autor: ASSIS,D.C.; OLIVEIRA,D.E. } \\
& \text { e PIMENTEL,F.O. } \\
& \text { Data: Janeiro/2017 }
\end{aligned}
$$

\section{IABOBATÓBIO DE CIIMATOLOEIA} faNällse ANBIERTAL

Fonte: os autores, 2017. 
Analisando a figura 8, chegou-se à conclusão de que poderia haver uma influência do fundo de vale localizado próximo à RU Morro da Glória no direcionamento dos ventos nos pontos 7 e 4, que de manhã seguem o direcionamento Vale $=>$ Morro, e a tarde Colina $=>$ Morro. $\mathrm{O}$ aquecimento diferencial do ar que ocorre diariamente formaria brisas de vale e de montanha (VIANELLO e ALVES, 2012).

Figura 8 - Fluxo dos ventos

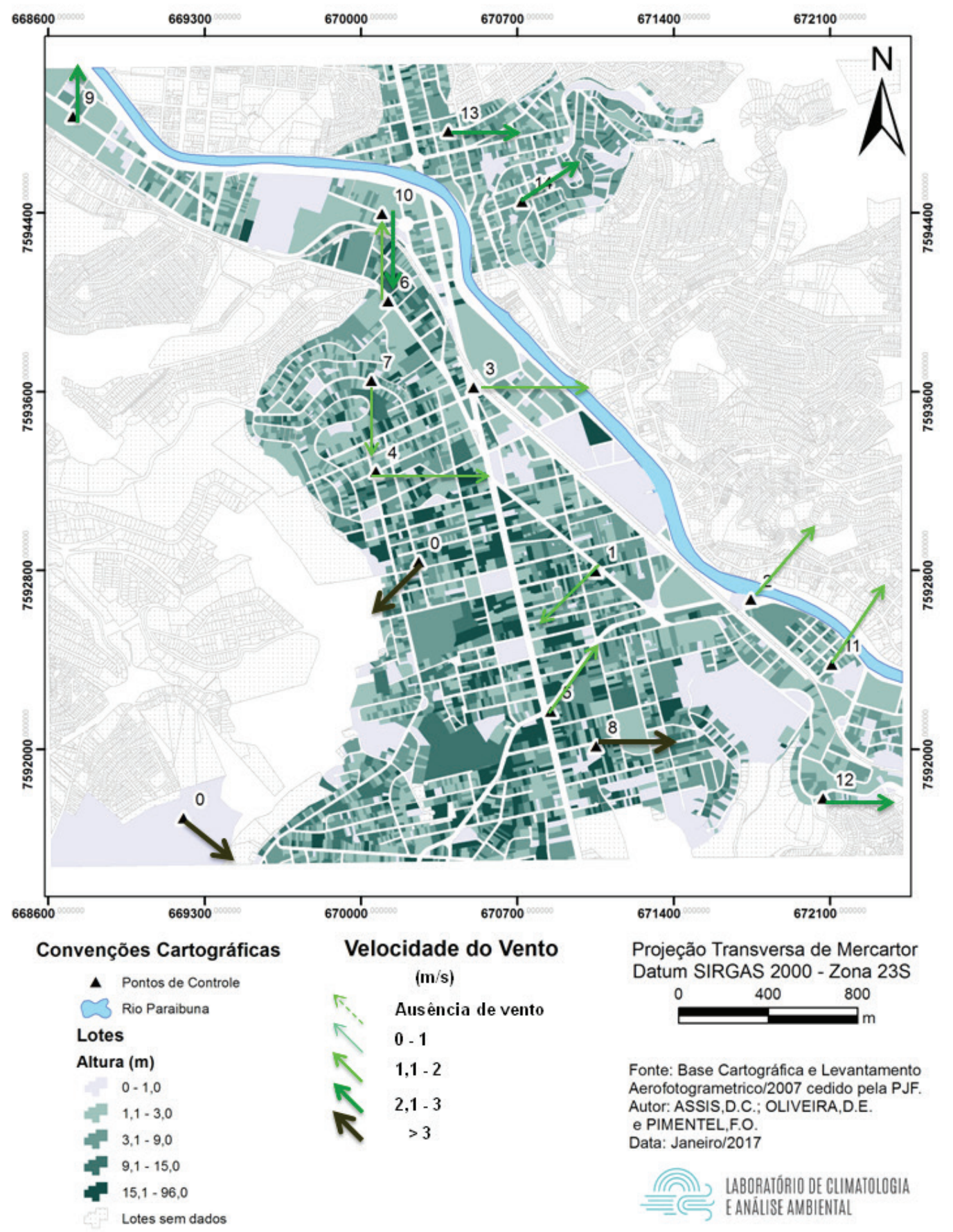

Fonte: os autores, 2017. 
Por sua vez, a direçáo predominante do ponto 5 pode estar relacionada ao fato de a avenida Itamar Franco ser formada por prédios elevados, que canalizariam os ventos locais e que seriam intensificados pelo fato de essa cortar a cidade e se iniciar em uma área elevada (próxima ao campus da UFJF), servindo de corredor de ventos para que o ar de camadas superiores também estejam sendo canalizados.

\section{CONCLUSÃO}

Através deste estudo foi possível verificar alguns padróes na dinâmica dos ventos, como a inter-relação com a temperatura do ar, uma vez que, com o seu aumento, foi detectado uma maior velocidade do vento. Observou-se também a atuação da morfologia do relevo e da rugosidade do meio urbano nos delineamentos e direcionamentos dos ventos.

De maneira geral, observou-se que na região central a velocidade dos ventos ficou na maior parte dos pontos entorno de 1,1 a $2,0 \mathrm{~m} / \mathrm{s}$, sendo que essa faixa de velocidade não revela preocupaçáo com relação a desconforto da população citadina, porém alguns pontos específicos devem ser monitorados, pois apresentaram valores mais elevados, como é o caso do ponto de controle 8.

Destaca-se que o trabalho de campo ocorreu durante a atuaçáo da Massa Tropical Atlântica, que normalmente produz estabilidade atmosférica e ventos baixos, próximos à calmaria. Enfatizando, portanto, que as velocidades encontradas, mesmo sob condições térmicas e de corredores de ventos, espelham a dinâmica atmosférica regional, portanto, baixas velocidades, sendo, dessa forma, importante expandir o estudo para diferentes condiçóes atmosféricas e ver como se dá o comportamento do vento.

Além da velocidade, deve-se atentar que não houve um padrão definido de direção do vento, porém verifica-se que muitos pontos de controle apresentaram direcionamento para o quadrante Leste, variando entre os pontos colaterais NE-SE, o que ressalta que em meio urbano, dada a sua complexidade de materiais, inúmeros são os fatores produtores de vento.

Apesar de preliminar, o trabalho apresentou resultados coesos e que permitiram caracterizar algumas condições de ventilação da região central da cidade, que trarão subsídios a outros estudos de clima urbano, na medida em que favoreceu, além do seu reconhecimento, correlações com outras variáveis. 


\section{REFERÊNCIAS BIBLIOGRÁFICAS}

BARRY, Roger, G.; CHORLEY, Richard. J. Atmosfera, tempo e clima.9. ed. Porto Alegre: Bookmam, 2013.

BRITTO, Monique Cristine de. A dinâmica da violência: análise geográfica dos homicídios ocorridos em Juiz de Fora entre os anos de 1980 a 2012. 2013, 210 f. Dissertação (Mestrado em Geografia) - PPGEO /UFJF, Juiz de Fora, 2013.

ELY, Deise Fabiana. Teoriae Método da Climatologia Geográfica Brasileira: uma abordagem sobre seus discursos e práticas. Presidente Prudente (SP): UEP/FCT-UNESP. 2006. 208 p. Tese. (Doutorado em Geografia).

INSTITUTO BRASILEIRO DE GEOGRAFIA E ESTATÍSTICA (IBGE), Censo Demográfico, 2010. Disponível em:<http://www.ibge.gov.br/home/estatistica/populacao/ censo2010/>. Acesso em: 12 dez. 2016.

MASCARO, Lucia Raffo. Energia na edificação: estratégia para minimizar seu consumo. São Paulo: Projeto, 1991.

MENDONÇA, Francisco; DANNI-OLIVEIRA, Inês Moresco. Climatologia: noções básicas e climas do Brasil. São Paulo: Oficina de Texto, 2007.

MONTEIRO, Carlos Augusto de Figueiredo; MENDONÇA, Francisco. Clima Urbano. São Paulo: Contexto, 2009.

NUNES JUNIOR, Eder Rodrigues. Metodologia de projeto de turbinas eólicas de pequeno porte. 2008, 188 f. Dissertação (Mestrado em Engenharia Mecânica). Rio de Janeiro, 2008.

ROCHA, Geraldo Cesar. Riscos Ambientais: análise e mapeamento em Minas Gerais. Juiz de Fora, MG: UFJF, 2005.

SANT'ANNA NETO, João Lima. História da climatologia no Brasil: gênese e paradigmas do clima como fenômeno geográfico. 169 f. Tese (Livre Docência). FCT , UNESP, São Paulo, 2001.

SANTIAGO, Barbara da Silva. Paisagem e fragmentação florestal no município de Juiz de Fora, MG. 114 f. Dissertação (Mestrado em Ciência Ambiental) UFF, Rio de Janeiro, 2008.

TASCA, Luciane. As contradições e complementaridades nas leis urbanas de Juiz de Fora. 2010, 249 f. Tese (Doutorado em Planejamento Urbano e Regional) UFRJ, Rio de Janeiro, 2010

TORRES, Felipe Tamiozzo Pereira. Relações entre fatores climáticos e ocorrências de incêndios florestais na cidade de Juiz de Fora (MG). Revista Caminhos de Geografia, Uberlândia, 2006.

VIANELLO, Rubens Leite; ALVES, Adil Rainier. Meteorologia básica e aplicações. Viçosa: UFV, 2012. 